\title{
Experimental Investigation of Stability and Structure of Vertical LPG Inverse Diffusion Flames Issuing from an Elliptic Burner
}

\author{
A. A. Mahgoub*, A. M. Hussien and K. A. Emara \\ Department of Mechanical Power Engineering, Faculty of Engineering at El-Mataria, \\ Helwan University, Massaken El-Helmia, P.O. 11718, Cairo, Egypt. \\ *Corresponding author: Ahmed_mahgoub93@m-eng.helwan.edu.eg
}

\begin{abstract}
The present paper experimentally examines the influence of the progressive variations of the central air jet velocity in a concentric circular-elliptical inverse diffusion flame (IDF) on the visual and thermal structure and stability of the developed flames. All experiments are conducted at a fixed fuel flow rate (liquefied petroleum gas) throughput that emerges from the annular elliptic passage having an aspect ratio of $2: 1$. The visual images are aided via a digital camera and shadowgraphs, while the thermal structure (axial and radial temperature profiles) is acquired using a bare fine wire $(125 \mu \mathrm{m})$ thermocouple; rendering radiation loss insignificant. The visual images and shadowgraphs clearly indicate the existence of four regimes: (i) an annular partially premixed region at the burner rim, (ii) an inner central premixed blue flame, (iii) an outer luminous yellowish post combustion zone and (iv) the flame tip buoyant zone. The progressive increases of the central average air velocity $\left(\bar{V}_{a}=7.4 \mathrm{~m} / \mathrm{s}\right.$ up to $\left.31.3 \mathrm{~m} / \mathrm{s}\right)$ result in shortening the visible flame length and narrowing the flame width. These are coupled with changing the flame appearance from a yellowish diffusion flame with a sooty core regime to an intense central premixed flame surrounded by a soot ring to blue flames exhibiting intense central radiation regime associated with soot oxidation. At extremely high air velocity $>21 \mathrm{~m} / \mathrm{s}$, locals flame extinction and re-ignition occurs at the boundaries of the ellipse minor axis and further increase of $\bar{V}_{a}$ causes complete extinction of the main flame. These findings are very much supported by the mean gas temperature measurements that indicate steep temperature rise associated with the formation of a central premixed combustion within the flame core which is followed by the diffusion mode of combustion. A plateau of the axial temperature profiles is observed in the transition zone between the two regions whereby the rise in temperature due to soot oxidation is balanced by the radiation loss.
\end{abstract}

Keywords: Inverse diffusion flame, Elliptic burner, Liquefied petroleum gas, Flame structure, Flame stability 


\section{Nomenclature}

$\mathrm{L}_{\mathrm{f}} \quad$ Visible flame length measured from burner exit to flame tip [mm]

$\bar{V}_{a} \quad$ Averaged velocity of the central air jet $\quad[\mathrm{m} / \mathrm{s}]$

$\bar{V}_{f} \quad$ Averaged velocity of the fuel jet $[\mathrm{m} / \mathrm{s}]$

y Height vertical distance measured from burner exit [mm]

\section{Introduction}

Diffusion (non-premixed) flame represents one of the most common flame configurations in the combustion systems. The inverse diffusion flame (IDF) is a distinct sort of diffusion flames, which varies from the ordinary diffusion flame in the relative position of air and fuel jets. In the IDF, a central air jet is surrounded by an outside fuel jet, and the fuel is entrained inward by the high-velocity jet of air and merges with the air to form a partially premixed flame. Otherwise, it could burn mainly in the diffusion mode. The normal diffusion flame has a broad flammability limit. While the premixed flame has the characteristics of low formation of soot. Inverse diffusion flame exhibits the characteristics of both premixed and non-premixed (diffusion) flames, hence, can exploit the advantages of both flames in term of stability limit improvement, lower pollutants, and operating safety. The IDF is cleaner than normal diffusion flame and is improbable to the lift off and flash back phenomena when compared to a premixed flame. Consequently, the feasibility of utilizing IDFs in domestic and industrial heating applications is of interest, [1-5].

The flame stability investigation is a key issue in any combustion research. The study of flame stability is essential to understand the operating range of the combustor. The flame stability of a laminar inverse diffusion flame was investigated in a previous study. It identified six different types of flames at a wide range of fuel and air velocities with a double concentric tube, Ref.[6]. Other studies reported the flame stability limits of turbulent IDFs for different burner configurations and different fuels, [3], [7]-[10]. The turbulent flame stability limits of a recessed and back step Co-axial burners was examined and it was observed that the back step burner flame has a lower flame stability limit than the coaxial IDF, [8]. An experimental study investigated the flame structure of a methane IDF and its dependence on central air and coaxial fuel velocities using OHPlaner laser-induced fluorescence (OH-PLIF) technique. Its $\mathrm{OH}$ measurements indicated local extinction occurrence, especially at the higher air-fuel velocity ratio, [9]. Another study introduced the stability limits and near blowout characteristics of unrecessed and recessed compressed natural gas $(\mathrm{CNG})$ inverse jet flames by varying air jet velocity at a constant fuel jet velocity. The results revealed that unrecessed flames have higher flame stability as compared to the recessed flames for the same fuel jet velocity, [10].

Numerous previous studies have already been performed to understand IDFs characteristics. The length of laminar IDF proportionally increases with the air flow rate, [11],[12]. The diameter of the nozzle and the flow rate of air and fuel also affect the structure, thermal characteristics, and flame length of IDF, [13]. The air-fuel ratio also has effects on the flame appearance and centerline temperature distribution,[14]. The 
effect of various air/fuel velocity ratio at a fixed fuel flow rate on the flame structure was studied to realize the role of mixing and entrainment in IDF, [9],[15]. The effect of burner configuration influences the thermal structure of the IDFs because of the mixing quality between fuel and air, [5]. Also, the diameter of the airport influences the characteristics the heat transfer of IDFs, [16]. The effects of Reynolds number and equivalence ratios on centerline temperature, flame shape and $\mathrm{CO}$ emissions are also reported, [17]. The characteristics of the swirl-stabilized IDF including heat transfer, flame appearance, and emissions are reported in, [1], [2], [18]. Other studies investigated the characteristics of the IDF experimentally as well as numerically, they investigated the flame appearance, centerline temperature distribution, and the flame length, [19], [20].

Some previous studies investigated the effect of burner tubes' shapes either circular or elliptical. The effects of elliptic and circle burner geometries on stability and global emission characteristics of premixed and partially premixed flames were reported in [21],[22]. They found that the elliptical burner geometry reduced the blowout stability. The premixed flames of elliptic burners characterize lower liftoff velocity, shorter, and lower heat radiation to the surrounding as compared to circular burner flames. Also, they produce higher peak in-flame temperatures and produced less peak NO as compared to circular burner, [23].

The concentric elliptic burners have also undergone several investigations with co- and cross-flow streams. The effect of elliptic burner orientation with respect to co-flow pipe on the stability limits and global emissions of diffusion flames were reported in [24]. It was found that elliptic burner diffusion flames when properly employed in elliptic coflow could reduce certain pollutants. Jet diffusion flames of another concentric elliptic burner with co- and cross-flow streams were examined in [25]. Shadow graphic imaging using ultraviolet laser was performed on non-premixed flame issuing from concentric elliptic burner, [26].

The demand for utilizing sustainable fuel sources in power generation and thermal processes has increased with the concern of the limited resources of petroleum-based fuels and greenhouse gases emissions. Liquefied petroleum gas (LPG) is considered in many research as one of the major future energy resources due to its wide availability [27], [28]. LPG characterizes clean, relatively low cost and abundant energy source, which drives the research to study its combustion characteristics to improve the prime movers efficiencies with reducing the $\mathrm{NO}_{\mathrm{x}}$ emissions, [28].

From the previous literature overview, it is found that the effect of elliptical burner shape on IDF characteristics was not well covered. So, the current study discusses the stability limits and structure of IDFs issuing from a concentric circular-elliptic burner. The effect of varying the central air velocity with constant fuel velocity on flame characteristics will be discussed. The study includes visual and shadowgraph imaging and inflame temperature measurements to investigate the flame structure. The flame images at different operating conditions are compared and analyzed. The analyses are focused on providing the associated variations in visible flame length, and shadowgraph imaging to show the details of different flame zones. The changes of axial and radial flame temperature inside the flame regimes are measured and analyzed for selected cases. 


\section{Experimental Setup, Facilities, and Program}

Figure (1) depicts the schematic diagram of the experimental setup, which contains the following:

\subsection{Burner test-rig}

The elliptic vertical burner shown in Figure (2) comprises of three concentric coaxial vertical tubes of stainless steel having a length of $300 \mathrm{~mm}$ each. The central round tube has an inner diameter of $8 \mathrm{~mm}$. The inner elliptic tube has major and minor axes of $30 \mathrm{~mm}$ and $15 \mathrm{~mm}$, respectively (Aspect ratio 2:1). The outer elliptic tube has major and minor axes of $70 \mathrm{~mm}$ and $35 \mathrm{~mm}$, respectively (Aspect ratio 2:1). Fuel (LPG) exits through the inner elliptic tube and the air (central air) exits through the central round tube. The outer air of the outer elliptic tube is turned off in the current study. The assembly of the burner can be traversed in the horizontal and vertical directions. The movements are implemented by linear DC motors to scan the flame radially and axially. The movements are controlled by a software (LabVIEW) with a resolution of up to $\pm 0.05 \mathrm{~mm}$. The test rig is housed inside a rectangle room having side glass walls to further prevent the effects of any natural drafts. The present experimental program for the whole investigated cases is summarized in Table (1).The fuel flow rate is adjusted at a fixed value of $0.4 \mathrm{l} / \mathrm{min}$ and the total flow rate of the central air is varied from 40 to $541 / \mathrm{min}$. The fuel used is liquefied petroleum gas (LPG) composed of $70 \%$ Butane $\mathrm{C}_{4} \mathrm{H}_{10}$ and $30 \%$ Propane $\mathrm{C}_{3} \mathrm{H}_{8}$, [28]. The fuel flow rate is electronically controlled by an ON/OFF solenoid valve through Lab VIEW program and measured by a calibrated ball rotameter having a full scale of $4 \mathrm{l} / \mathrm{min}$. The air is supplied from air compressor. The air pressure from the compressor is regulated by pressure regulator. The central airflow rate is controlled by a needle valve and measured by orifice meter with a U-tube manometer.

\subsection{Measuring systems}

\subsubsection{Flame visualization system}

A digital camera having a high resolution of 30.3 Megapixels is employed to obtain accurate, highly resolved, and colorful visual images of the flames under different operating conditions. These images allow obtaining both the visual flame length as well as identifying the different flame regimes.

\subsubsection{Shadowgraph imaging system}

The shadowgraph imaging of the investigated flames is obtained to differentiate between the flame zones. A low power 20-mW compact continuous wave (CW) $405 \mathrm{~nm}$ laser diode is used to backlight in order to generate a large flow field shadowgraph on a distant florescent screen. The florescent screen is made of a standard fluorescent sticker that appears pale under the illumination of burner flames but glows under ultraviolet and blue laser radiation (300-420 nm). A digital camera is used to image the flame shadows. The acquired images undergo processing sequence (a to c) to improve their quality and to clear their details, see Figure (3). Mathematica 12.1 software was used to process and analyze the acquired images. 
Adel Mohamed Hussien / Engineering Research Journal 171 (September 2021) M33- M50

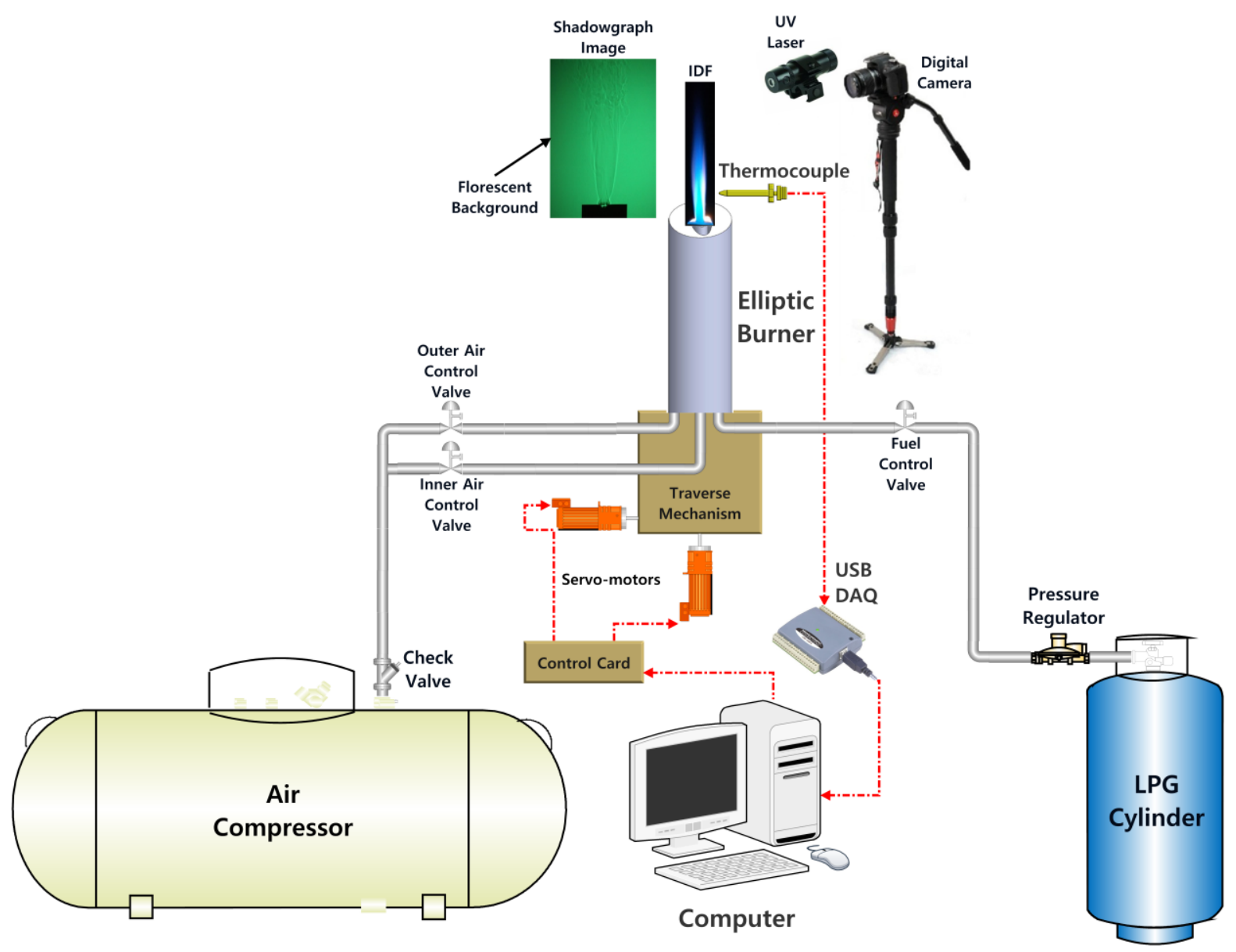

Figure (1) Schematic diagram of the experiment set-up.
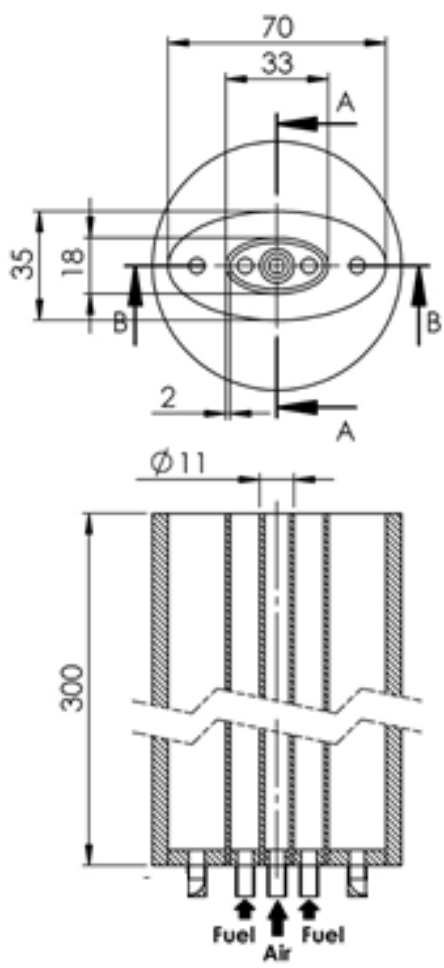
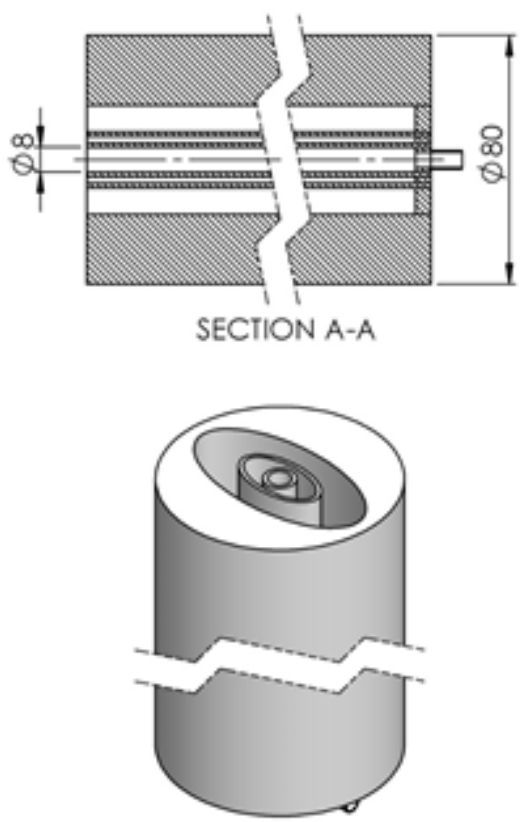

SECTION B-B

Figure (2) Elliptic burner details. 
Table (1) Experimental program.

\begin{tabular}{ccccccc}
\hline Run & $\bar{V}_{f}[\mathrm{~m} / \mathrm{s}]$ & $\bar{V}_{a}[\mathrm{~m} / \mathrm{s}]$ & $\begin{array}{c}\text { Visual } \\
\text { Imaging }\end{array}$ & $\begin{array}{c}\text { Shadowgraph } \\
\text { Imaging }\end{array}$ & $\begin{array}{c}\text { In-Flame } \\
\text { Temperature }\end{array}$ \\
\hline A & 0.026 & 13.26 & $\sqrt{ }$ & $\sqrt{ }$ & Axial \\
B & 0.026 & 14.42 & $\sqrt{ }$ & $\sqrt{ }$ & Axial \\
C & 0.026 & 15.58 & $\sqrt{ }$ & $\sqrt{ }$ & Axial \& Radial \\
D & 0.026 & 16.74 & $\sqrt{ }$ & $\sqrt{ }$ & Axial \\
E & 0.026 & 17.90 & $\sqrt{ }$ & $\sqrt{ }$ & Axial \\
\hline
\end{tabular}

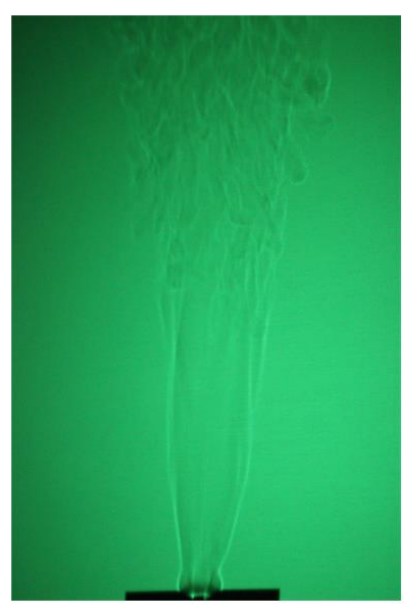

(a)

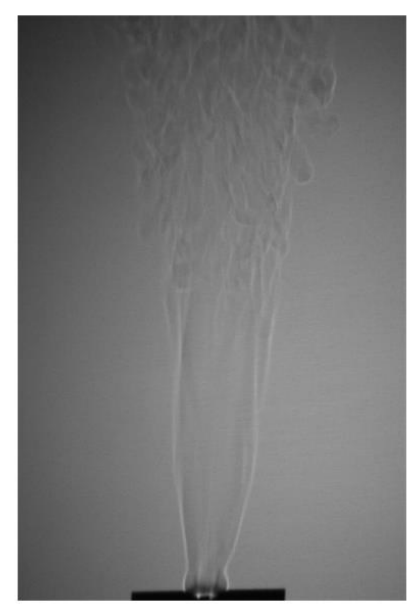

(b)

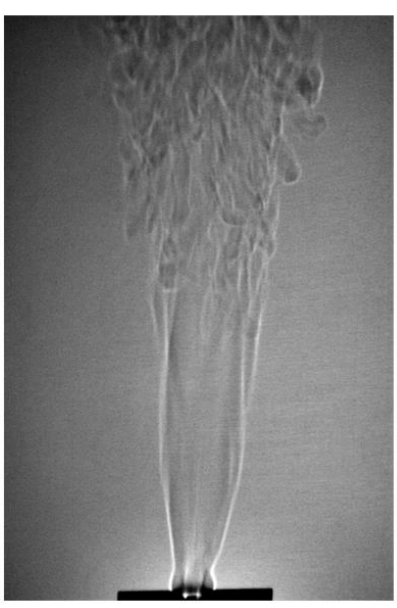

(c)

Figure (3) Image processing sequence for shadowgraph imaging, (a) raw image, (b) gray-scale image, and (c) sharpen image.

\subsubsection{In-flame temperature measurement}

Mean in-flame temperature was obtained by a $125 \mu \mathrm{m}$ platinum/platinum $10 \%$ Rhodium (type-S) wire thermocouple. The signal of the thermocouple is digitized by the usage of the Omega USB reader and its interface software by connecting to the PC. Radiation corrections were performed as in, [29], assuming a thermocouple emissivity of 0.2. The radiation corrections never exceed $30^{\circ} \mathrm{C}$, giving further support to the previous findings that radiation loss could be ignored for fine wire thermocouples, [30].

\section{Results and Discussion}

\subsection{IDF structure}

All IDFs comprise base and main flames (dual structure) as depicted in Figure (4-a). The base flame is two crescent-shaped lower parts of the IDF between the flame neck and the burner exit, also known as the entrainment zone, where the fuel is entrained towards the central air jet, as depicted in Figure (4-b). At the flame base, a portion of the fuel burns in diffusion mode, and the other portion is entrained into the central air jet to burn premixed mode. The base flame is serving as a pilot flame, which heats the incoming reactants to stabilize the main flame. The main flame is the upper part of the IDF ensuing from the neck of the flame and contains the post- combustion zone and the inner reaction zone (blue zone), as depicted in Figure (4-b). The base and main flames are separated by a flame neck region with a yellow soot ring surrounds the flame neck [3]. The IDFs have unique flame characteristics including a base flame that is absent in 
NDF configurations. Moreover, the central airflow rate is in the turbulent regime and the fuel flow rate is in the laminar regime, [3], [20].

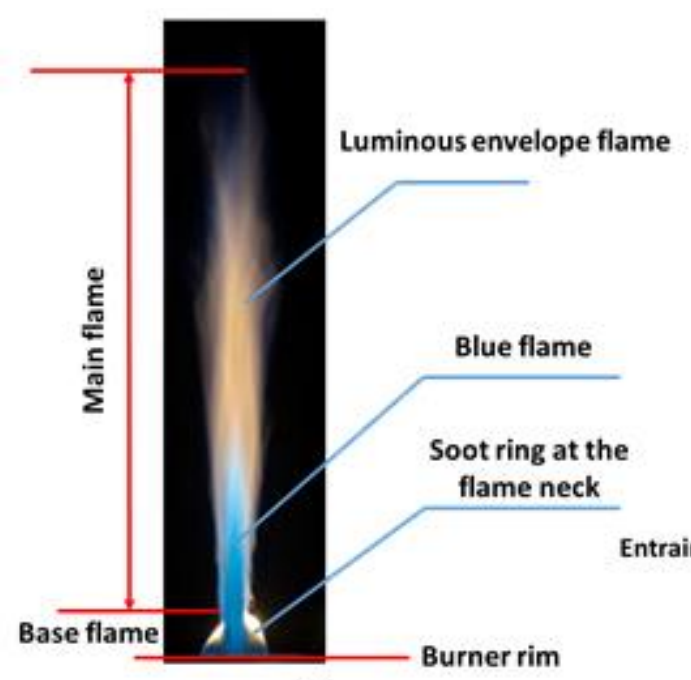

(a)

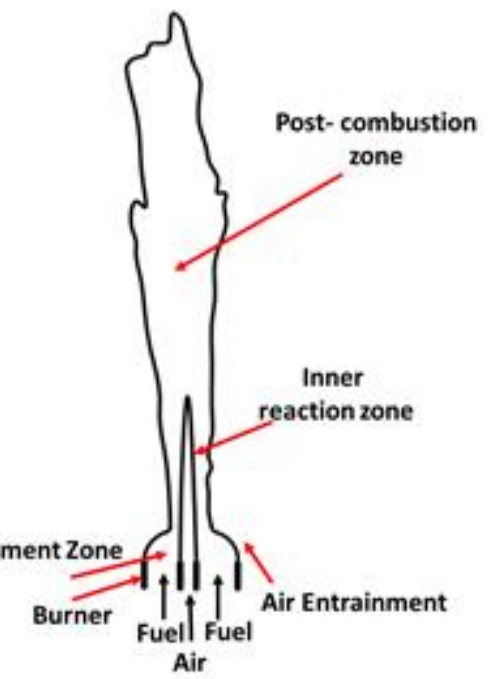

(b)

Figure (4) (a) Image of IDF appearance and (b) Schematic structure of IDF flame

\subsection{Flame stability}

The flame stability of IDFs is an essential parameter used to determine the range of operating conditions that can sustain a stable flame. A flame is considered stable if it was free of main flame local extinctions and it worth mention that there is no total flame blow-off for the current burner configuration. The flame stability in the current study of the LPG IDFs for the elliptic burner is investigated by varying the airflow rate at a fixed fuel flow rate. The following sections include analysis of the appearance and stability characteristics of LPG IDFs of the elliptic burner over a wide limit of operating conditions.

\subsubsection{Flame appearance}

As depicted in Figure (5), the effect of the central air jet velocity at constant fuel flow velocity of $0.026 \mathrm{~m} / \mathrm{s}$ on the visual flame appearance is examined. It is important to obtain a change in the overall equivalence ratio with maintaining a fixed thermal input. At the lower central air jet velocity $\left(\bar{V}_{a}=7.4 \mathrm{~m} / \mathrm{s}\right)$, the flame has a similar appearance to a pure normal diffusion flame. The fuel burns with the air entrained from its surroundings, and the flame is highly luminous due to the soot incandescence. For a certain range of air velocity $\left(\bar{V}_{a}=11.7-17.9 \mathrm{~m} / \mathrm{s}\right)$, an IDF is established inside an ordinary diffusion flame. Similar flames were observed and reported in previous studies, [4], [13]. The IDF with lower blue zone enveloped by a luminous zone is observed in Figure (5b) for a central air velocity $\left(\bar{V}_{a}=11.7 \mathrm{~m} / \mathrm{s}\right)$. The blue flame with a soot ring at the neck of the flame is observed in Figure (5b-d) for a central air velocity range $\left(\bar{V}_{a}=18.6-17.6 \mathrm{~m} / \mathrm{s}\right)$, and the main flame becomes non-luminous because of improvement of partial premixing between air and fuel caused by air momentum increasing. Also, the soot ring decreases with increasing the air velocity due to combustion enhancement.

With increasing the air jet velocity $\left(\bar{V}_{a}=21.9-26.4 \mathrm{~m} / \mathrm{s}\right)$, the main flame faces local extinctions and re-ignitions (flame tearing) as observed in Figure (5e-f). This is caused by an increasing in the strain rate. The strain rate parameter is determined by $\left(\bar{V}_{a}-\bar{V}_{f}\right)$ 
$/ \mathrm{D}$, where $\mathrm{D}$ is the diameter of central air pipe. With increasing the air velocity $\left(\bar{V}_{f}>31.3\right.$ $\mathrm{m} / \mathrm{s}$ ), higher strain rate occurs at the air and fuel streams interface, which can cause the intense interaction of the vortical structure in the shear layer with the main flame, [7]. This leads to the disappear of the re-ignition phenomenon, which leads to main flame extinction as observed in Figure $(5 \mathrm{~g})$.

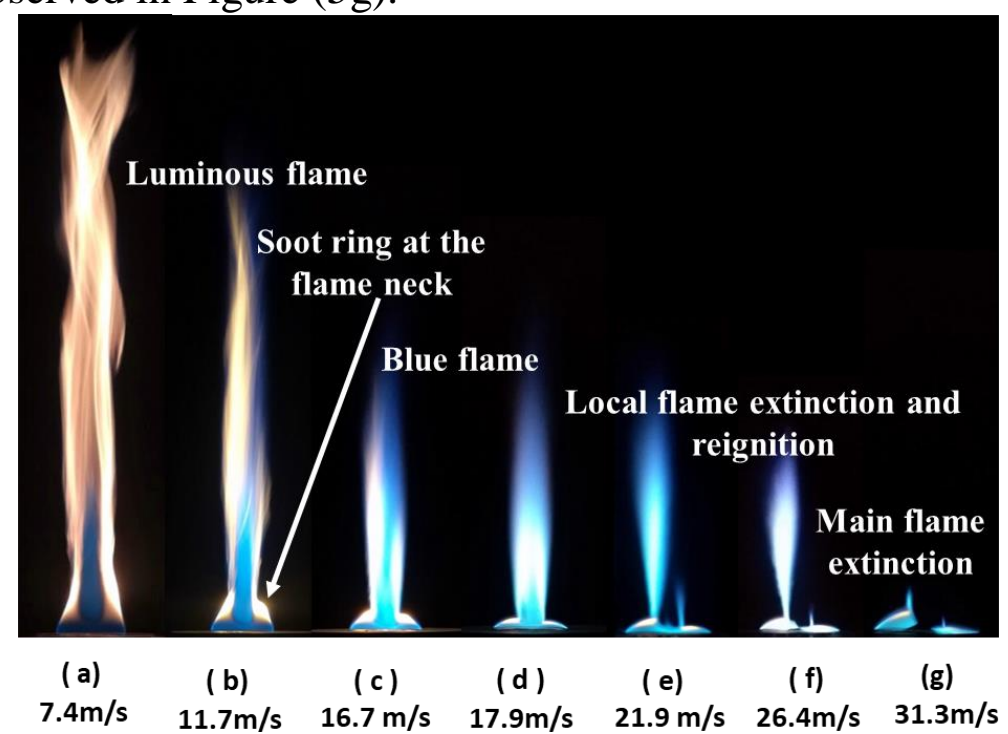

Figure (5) The flame appearance with increasing air velocity $\bar{V}_{a}$ at a constant fuel velocity $\bar{V}_{f}=0.026 \mathrm{~m} / \mathrm{s}$.

\subsubsection{Flame stability characteristics}

The flame stability mapping was implemented by varying air velocity with constant fuel velocity as depicted in Figure (6). The flame stability regions comprise of yellow flame, blue flame, local flame extinction and re-ignition, and main flame extinction. For the current burner configuration, the operating conditions at very low air velocity led to normal diffusion flames. The IDF with lower blue zone enveloped by luminous zone appears at the upper region of the yellow flame zone. The blue flame zone lies above the yellow flame zone up to the air velocity value of $22 \mathrm{~m} / \mathrm{s}$. Because of the enhanced mixing among fuel and air, the flames become momentum dominated instead of diffusion dominated that makes the flames blue.

The almost-constant air velocity value of $22 \mathrm{~m} / \mathrm{s}$ forms a strain rate limit for the stable blue flames in conjunction with the fuel properties (i.e., burning velocity). With air velocity higher than $22 \mathrm{~m} / \mathrm{s}$, the local extinction and re-ignition zone begins. With increasing air velocity, the interaction of the main flame with shear layer vortices can result in the greater flame stretch which can perform to main flame extinction. The main flame extinguishes from the neck of the flame while the base flame remains attached to the burner edge. The main flame extinction zone occurs for air velocity higher than $32 \mathrm{~m} / \mathrm{s}$. The main flame extinction limit increases slowly up to a constant fuel velocity of $0.056 \mathrm{~m} / \mathrm{s}$. It is important to observe that the main flame extinction limit keeps almost unchanged for the fuel velocity range of $0.056-0.064 \mathrm{~m} / \mathrm{s}$. The main flame extinction occurs because of high strain rates at the interface of the base and main flames accompanied by high rates of heat dissipation due to the high core momentum, [7]. Moreover, the equivalence ratio of the mixture at the main flame decreases significantly with an increase in the strain rate due to ambient air entrainment,[7]. It is remarkable to note that the flame lift-off phenomenon is absent because the base flame stabilizes and 
anchors the main flame to the rim of the burner. This is due to the base flame is stabilized with the surrounding air like a normal diffusion flame.

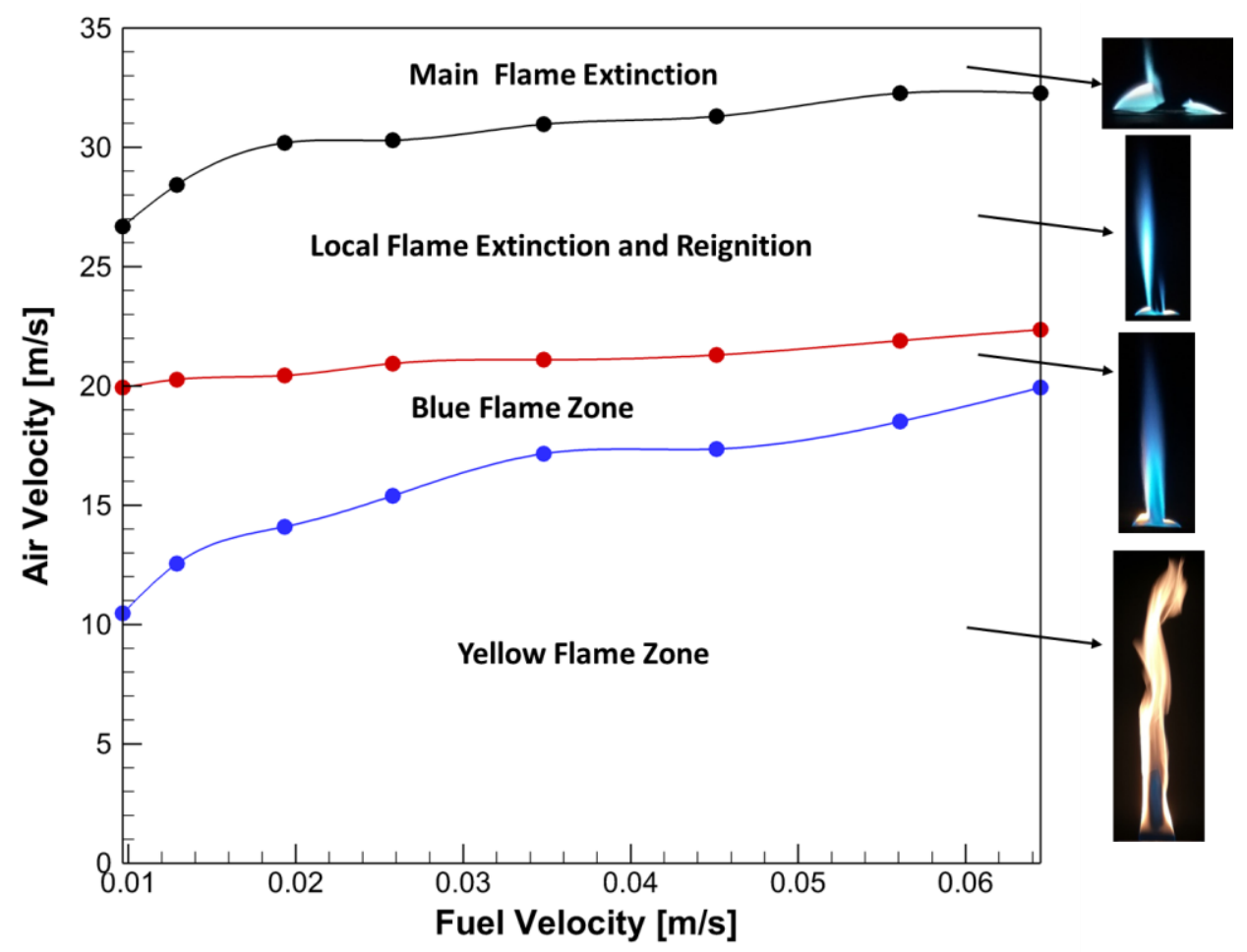

Figure (6) Flame stability map for the current burner configuration.

\subsection{Varying central air velocity at constant thermal input}

\subsubsection{Flame appearances}

The appearance of the flames helps in understanding the physical processes involved in the IDF combustion. The IDF's appearance relies on the burner configuration, the air velocity jet, and the fuel velocity. The IDF images with increasing air jet velocity, $\bar{V}_{a}=13.26$ to $17.9 \mathrm{~m} / \mathrm{s}$ at fixed fuel velocity $\bar{V}_{f}=0.026 \mathrm{~m} / \mathrm{s}$ for major and minor axes are shown in Figure (7) and Figure (8). The enhanced mixing between air and fuel jets with increasing the air velocity is evident of an absent luminous zone. Moreover, the flame is observed to become thinner with air velocity increase. Due to the fuel is introduced through an elliptical tube around the circular air jet, a non-homogenous fuel distribution through the entraining air jet is existing. This leads to reshaping the flame on both major and minor axes of the elliptic fuel tube.

For Runs A and B, the blue zone enclosed by a luminous zone of the IDF was previously mentioned by $\mathrm{Wu}$ and Essenhigh, [6]. The formation of the luminous zone is due to the low air jet momentum, which reduces the effectiveness of fuel-air mixing. The increase in the velocity of the central air jet reduces the flame luminosity in the upper portion of IDF as observed in (Run C). The reduced flame luminosity with an increase in air jet velocity is an indication of reduced soot formation. It is evident that the soot ring at the top of the flame base in IDF refers to soot formation, which is attributed to the nonpremixed combustion of the fuel. With increasing the air velocity, both the luminous zone and the soot ring decrease (Run D and E). The higher entrainment of the annular fuel jet by the central air jet enhances the air-fuel mixing that imparts a partially premixed structure to the IDF. It can be noted that with increasing the central air jet 
velocity, the length of the IDF is reduced, as shown in Figure (7) and Figure (8). It should be noted that for a fixed fuel jet velocity, the IDF main flame becomes locally lean with an increase in air jet velocity. Also, the main flame entrains more air from the ambient, that can create its local equivalence ratio further leaner.

In a pure normal diffusion flame, the fuel is burned with an entrained air from the surrounding; thus, the flame is yellow. In IDFs, the central air jet drags the fuel jet. The degree of fuel entrainment by the air jet determines the degree to that the fuel is burned in the premixed mode or diffusion mode. Change in the color of the IDF is an indication of the effect of the entrainment of the fuel jet. It can be observed that the increasing air velocity jet enhances the entrainment of the fuel jet, which, performs to more fuel burnt in the premixed mode, [2]. The same influences of air jet velocity on color and flame length have been reported in, [2],[5]. Finally, at higher air jet velocity, stronger entrainment and turbulence aid mixing among fuel and air, so that the flame becomes more intense and shorter.

\subsubsection{Visible flame length}

In addition to the flame appearance, the visible length of the flame is a significant feature of the IDFs. The visible flame length is an important parameter to describe IDFs, which aid in estimating the range of mixing in air/fuel jets and it is an indication for the residence time. It is a significant to relate the visible flame length with dominant parameters such as exit tube diameters and air/fuel jet velocities, which will be helpful in designing practical combustion processes. The visible flame length is defined as the summation of the base flame and main flame lengths.

In the present study, the visible flame length of LPG IDFs is investigated by varying the central air jet velocities at a constant fuel jet velocity, $\bar{V}_{f}=0.026 \mathrm{~m} / \mathrm{s}$ as shown in Figure (9). It can be found that there is a decrease in visible flame lengths (blue curve) with the increase of central air jet velocity for a constant fuel jet velocity, [2], [13], [14]. The flame length, $\mathrm{L}_{\mathrm{f}}$, is affected by the relative velocity between air and fuel jets $\left(\bar{V}_{a}-\bar{V}_{f}\right)$. The increasing in the relative velocity between fuel and air jets causes an increase in the shear between them. The shear increases the turbulence intensity which enhances the air-fuel mixing resulting in a shorter flame. Also, the length of the base flame (red curve) decreases almost linearly and changes very little with the increase in the central air jet velocity. This is because the central air entrains more fuel and ambient air, [31].

\subsubsection{Shadowgraph imaging}

Shadowgraph imaging is an ultra-simple method to generate a large flow field shadowgraph and show the details of different flame zones. The shadowgraph images evident flame zones that do not appear in the normal flame visual imaging. Figure (10) and Figure (11) compare the shadowgraph images of the IDFs with varying the air velocity at a constant fuel velocity for the major and minor axes. With increasing the air velocity, the air entrainment increases as shown in Figure (10), where the outer flow shield moves inward to the inner flow jet. Also, more excessive interaction of the vortical structure in the shear layer with the inner jet, see Figure (11). Increasing the air velocity led to increasing corrugation in the flames. This is an indication that the flame length decreases with increasing the air velocity. 

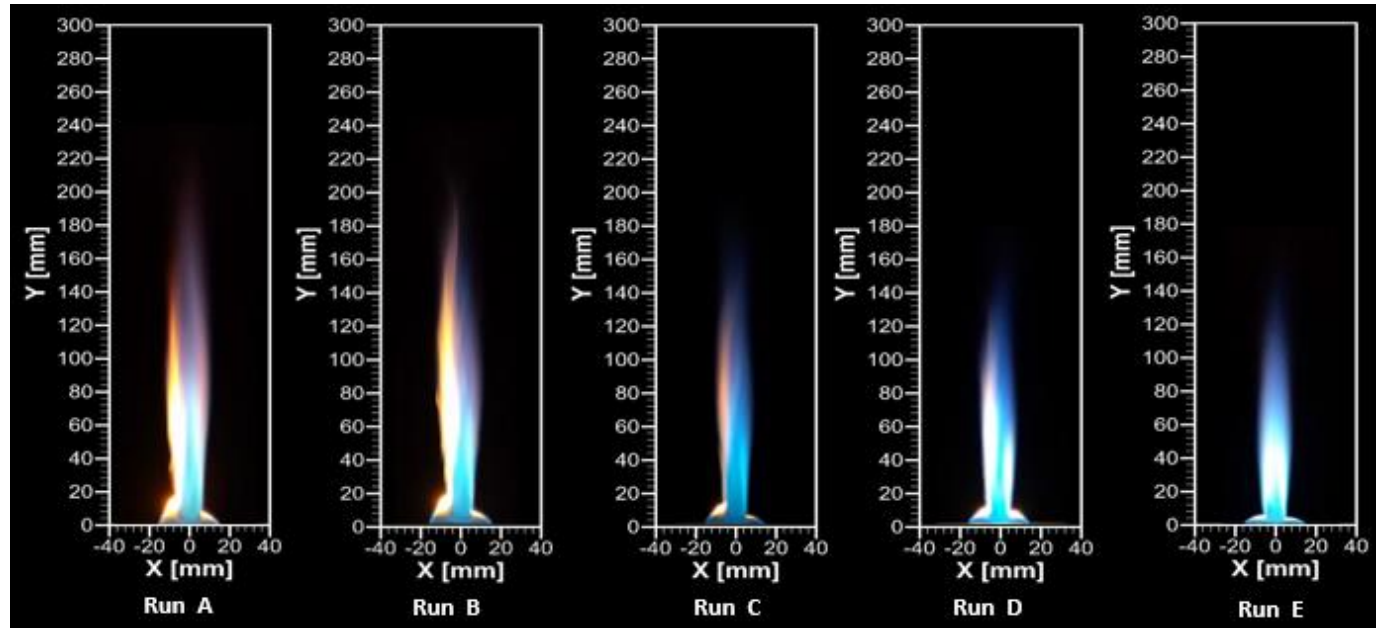

Figure (7) IDF images with varying central air velocities, $\bar{V}_{a}$ at a constant fuel velocity, $\bar{V}_{f}=0.026 \mathrm{~m} / \mathrm{s}$ for major axis.
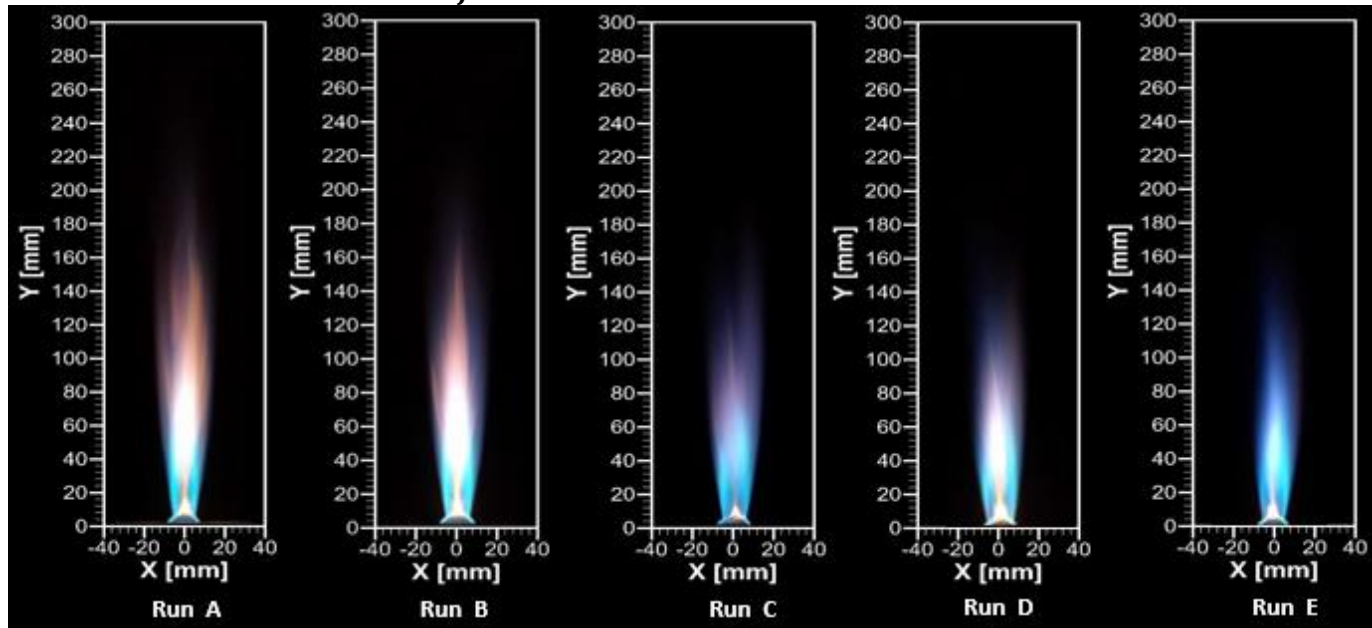

Figure (8) IDF images with varying central air velocities, $\bar{V}_{a}$ at a constant fuel velocity, $\bar{V}_{f}=0.026 \mathrm{~m} / \mathrm{s}$ for minor axis.

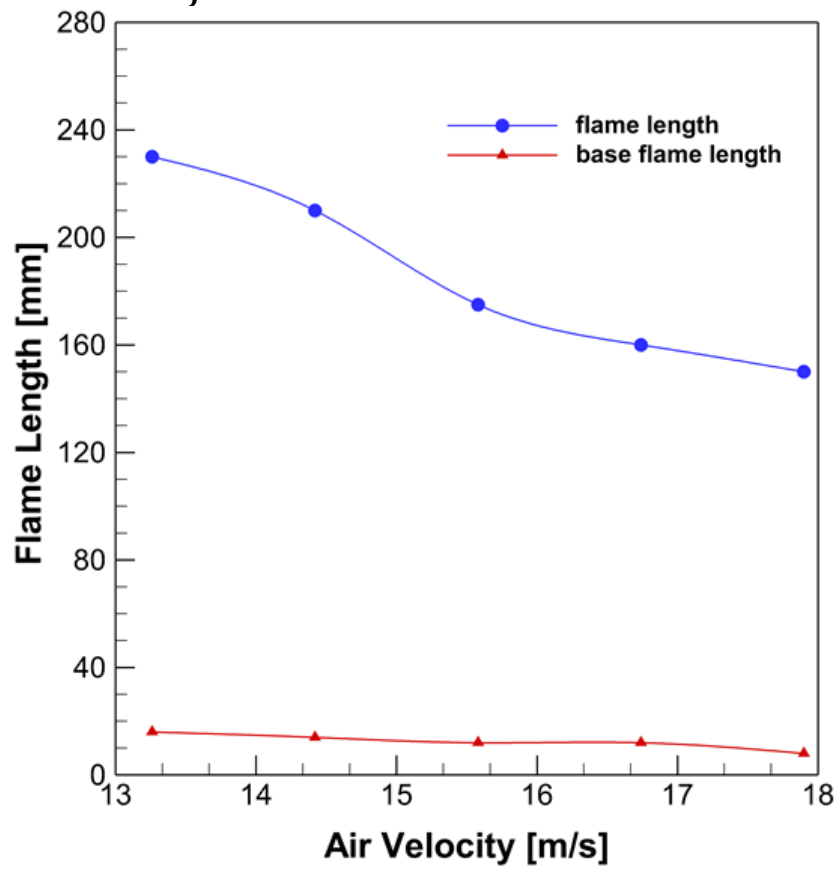

Figure (9) Visible Flame length variations with different air velocity at a constant fuel velocity of $\bar{V}_{f}=0.026 \mathrm{~m} / \mathrm{s}$. 


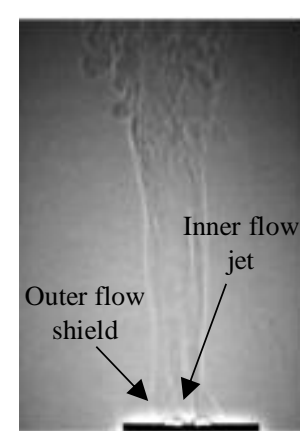

(a) Run A

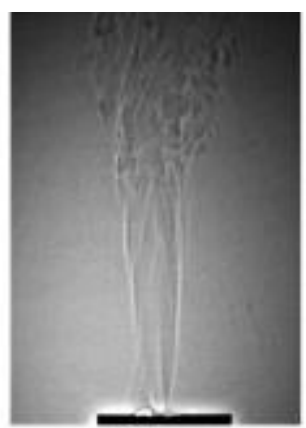

(b)

Run B

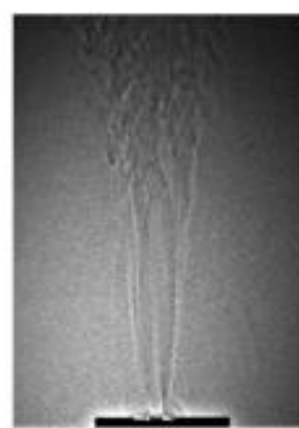

(C)

Run C

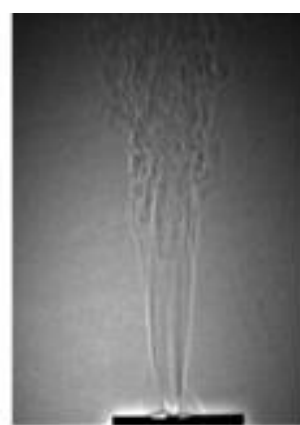

(D)

Run D

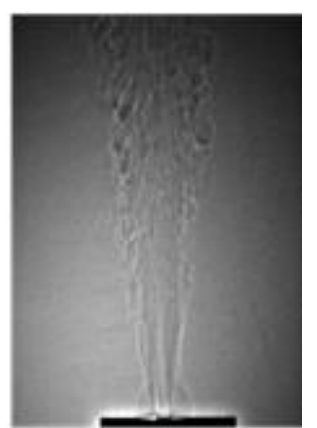

(E)

Figure (10) Shadowgraph images of IDFs with varying central air velocity at a constant fuel velocity, $\bar{V}_{f}=0.026 \mathrm{~m} / \mathrm{s}$ for major axis.

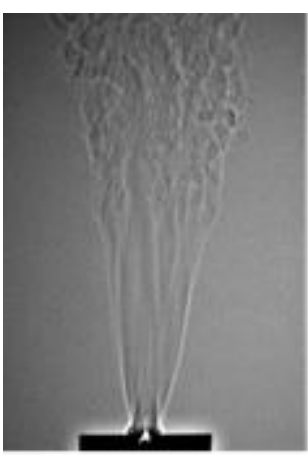

(a)

Run A

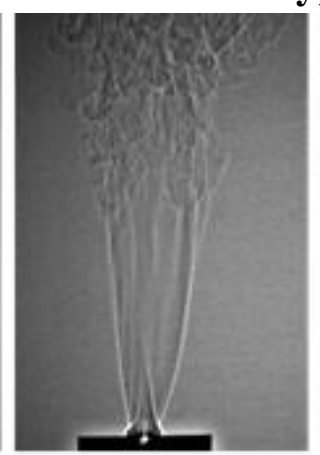

(b)

Run B

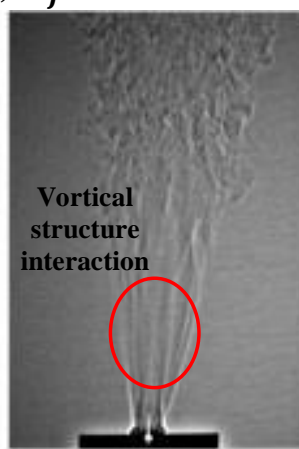

(C)

Run

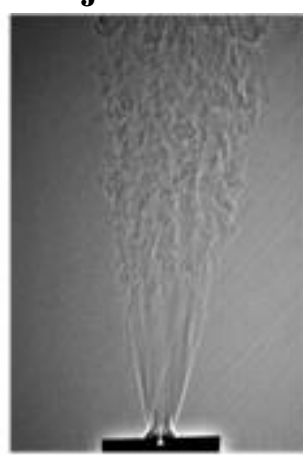

(D)

Run

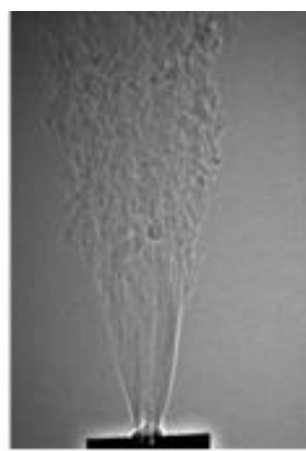

(E)

Run E

Figure (11) Shadowgraph images of IDFs with varying central air velocity at a constant fuel velocity, $\bar{V}_{f}=0.026 \mathrm{~m} / \mathrm{s}$ for minor axis.

\subsubsection{Axial and radial temperature measurement}

In order to understand the thermal structure of the IDFs, temperature profiles including the axial and radial temperature distributions and the temperature contour are introduced in the next sub-sections.

\subsubsection{Centerline Temperature Distribution (Axial Temperature)}

The mean centerline temperatures of the LPG IDFs versus the axial distance $y$ for varying air velocities with a constant fuel velocity are shown in Figure (12). Generally, the value of the peak means centerline temperature decreases with increasing the air velocity. This is because the air velocity increasing causes cooling down the flame core (central region) while the heat input remains constant, [32].

For all flames, the mean centerline temperature gradually increases in the vicinity of the base flame up to the value of axial distance an almost $(\mathrm{y}=40 \mathrm{~mm})$ from the burner rim. Then, the temperature increases by a very steep climb up to the blue zone (inner reaction cone). The temperature has almost close values (the peak) due to the color of central region evens out, [13]. The peak centerline temperature is reasonably coincident with the blue zone, [2]. However, the temperature gradually decreases as the axial distance ascends into the post combustion zone due to the heat release in the main flame is transported by convection. This is due to the entrained cold ambient air dilutes and cools down the combustion products. 
The maximum temperature position within the blue zone (inner reaction cone) exhibits position shifting while increasing the air velocity due to blue zone length variations, as shown in Figure (12). With increasing the air velocity from 13.26 to $14.42 \mathrm{~m} / \mathrm{s}$, the peak temperature position moves downstream the inner reaction zone. This is due to the inner reaction zone is reconstructed and grows up during the conversion from the normal diffusion flame to establish the IDF. While increasing the air velocity up to $17.9 \mathrm{~m} / \mathrm{s}$, the peak temperature position gradually moved upstream the reaction zone. This is attributed to the enhanced mixing between fuel and air, which leads to retract the inner reaction zone. This is an indication to a shorter flame as discussed earlier. For the air velocity of $17.9 \mathrm{~m} / \mathrm{s}$, the peak value slightly increases due to the flame slender.

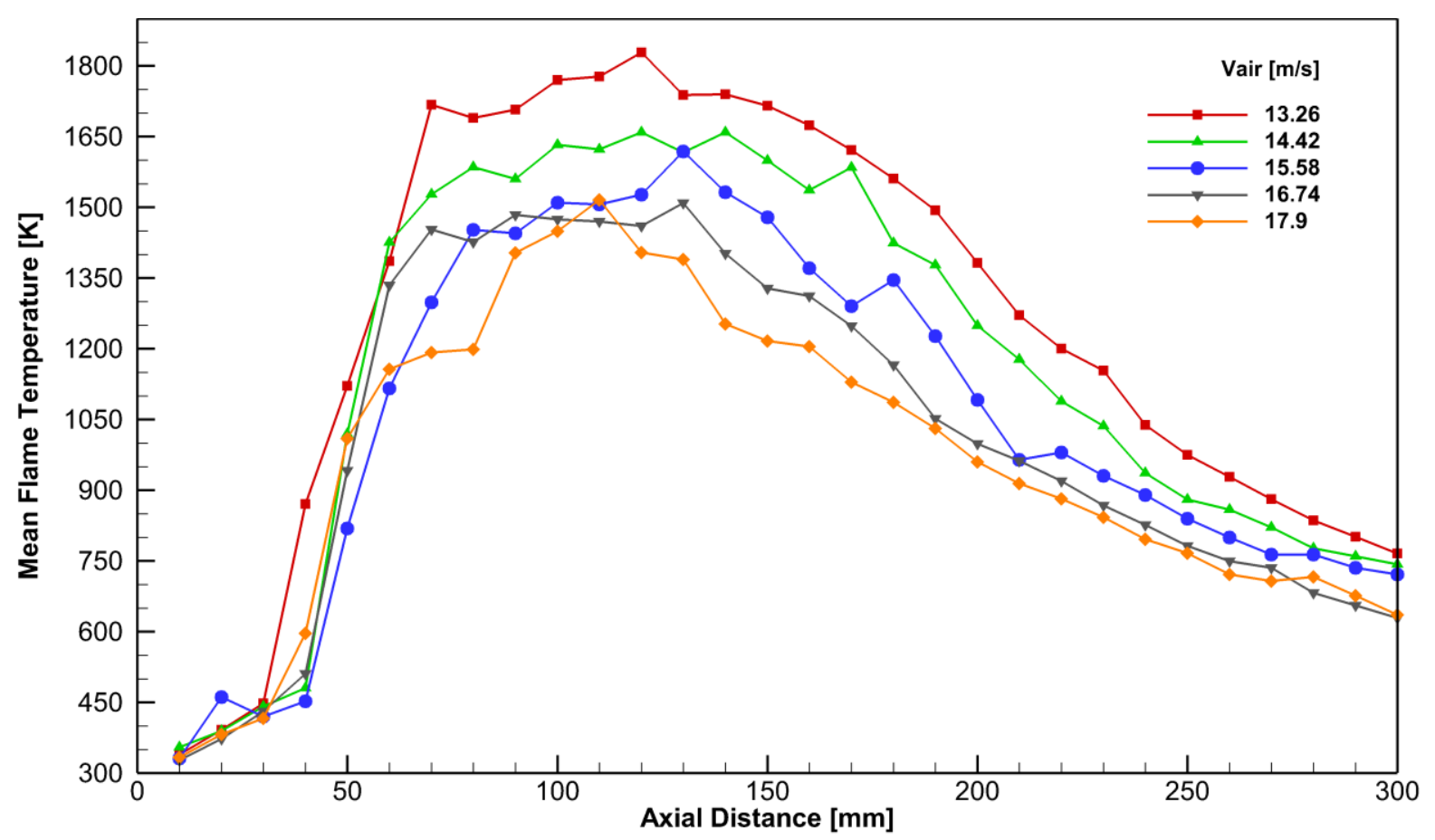

Figure (12) Centerline temperature distribution with different air velocity at constant fuel velocity of $\bar{V}_{f}=0.026 \mathrm{~m} / \mathrm{s}$.

\subsubsection{Radial Temperature}

Figure (13) shows radial profiles of temperature distribution for major and minor axes at different axial distance $(\mathrm{y}=30,60,120,180$ and $240 \mathrm{~mm})$ at $\bar{V}_{a}=15.58 \mathrm{~m} / \mathrm{s}$ and $\bar{V}_{f}=0.026 \mathrm{~m} / \mathrm{s}$. The temperature profile at $\mathrm{y}=30$ and $60 \mathrm{~mm}$, the temperature is low at the flame centerline and increases sharply in the radial direction to the peak and then falls rapidly. However, the temperature profile at $y=120 \mathrm{~mm}$ poses the same trend but with smoother variation. It is seen that the radial temperature profiles have peak values at the radial positions from 5 to $10 \mathrm{~mm}$ from the center-line. The rapid rise in the temperature is attributed to the preheating of the air-fuel mixture form the reaction (combustion) zone. After rising the mixture temperature to the reaction limit, the combustion occurs forming the reaction zone with the highest temperature. Due to the high entrainment of the ambient cold air, the temperature falls rapidly towards the outside of the flame in the radial direction. The centerline temperature has the highest value in the radial profiles 
for $\mathrm{y}=180$ and $240 \mathrm{~mm}$. This is attributed to the cold ambient air entrained into the flame that cools down the hot combustion products, [33].

Although the distributions of the radial temperature for the major and minor axes follow the same trend as shown in Figure (13), there is a difference between them. For the entire range of axial distance, the highest temperature on a minor axis is higher than that on the major axis. This is attributed to non-homogenous fuel distribution through the entraining air jet because the fuel is introduced through an elliptical tube around the circular air jet. Also, at $y=120 \mathrm{~mm}$, the temperature profile on minor axis is wider than the profile on the major axis, that is because the flame in the minor plane (parallel to the minor axis) is $\mathrm{V}$-shape.

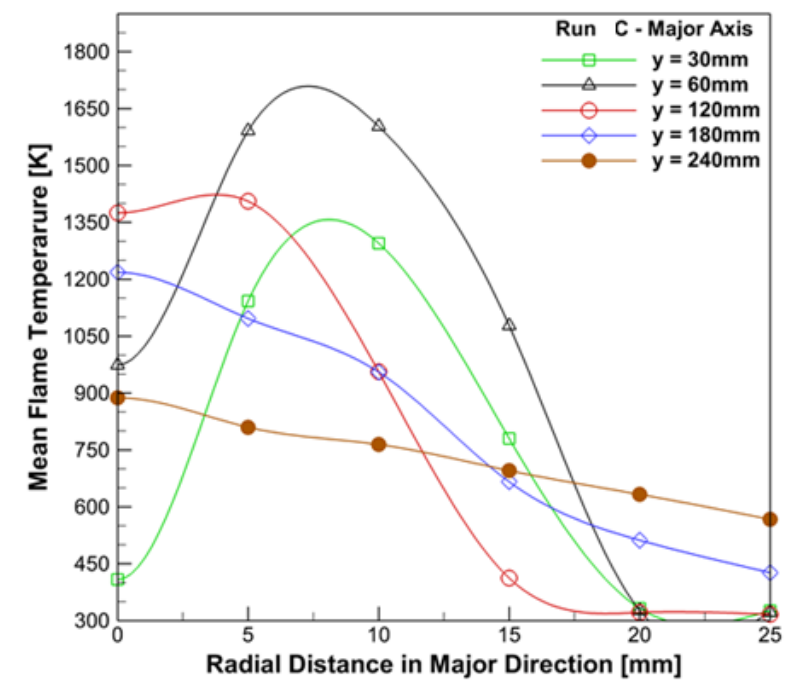

(a)

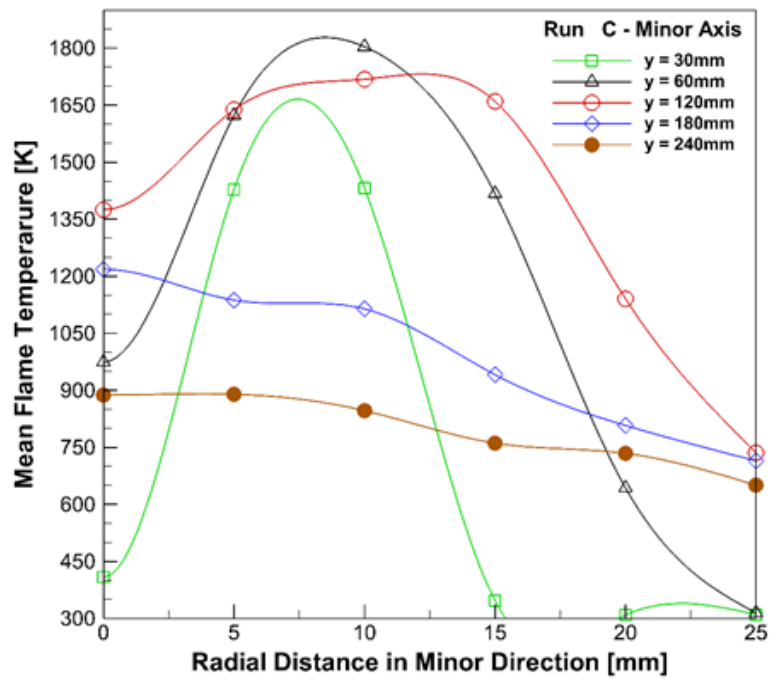

(b)

Figure (13) Radial temperature distribution at different axial distance, y, for $\bar{V}_{a}=15.58 \mathrm{~m} / \mathrm{s}$ and $\bar{V}_{f}=0.026 \mathrm{~m} / \mathrm{s}$; (a) Major direction (b) Minor direction.

The temperature contours for the major and minor axes under the same $\bar{V}_{a}$ and $\bar{V}_{f}$, are shown in Figure (14). The temperature distribution can be divided into four specific regions, namely: the base flame zone, mixing zone, main reaction zone, and postcombustion zone, [1],[33]. The base flame (entrainment zone) has relatively low temperatures due to the low-temperature fresh reactants. The base flame comprises a cool core which is located in the potential core region of the air jet. In the mixing zone, the flame temperature steadily increases from the flame neck due to the chemical reaction, while the temperature at the core of the flame is still cold due to the presence of the air jet at the flame axis. The main reaction zone (inner reaction cone) is typically associated with the maximum flame temperature. This is due to the completion of the air/fuel mixing process and the release of more heat. The post-combustion zone is associated with the decrease in the temperature due to the entrainment of ambient air that cools down the hot combustion products, as well as the lower liberated heat. It can be observed that the temperature contours are dense in the closeness of main reaction zone. 


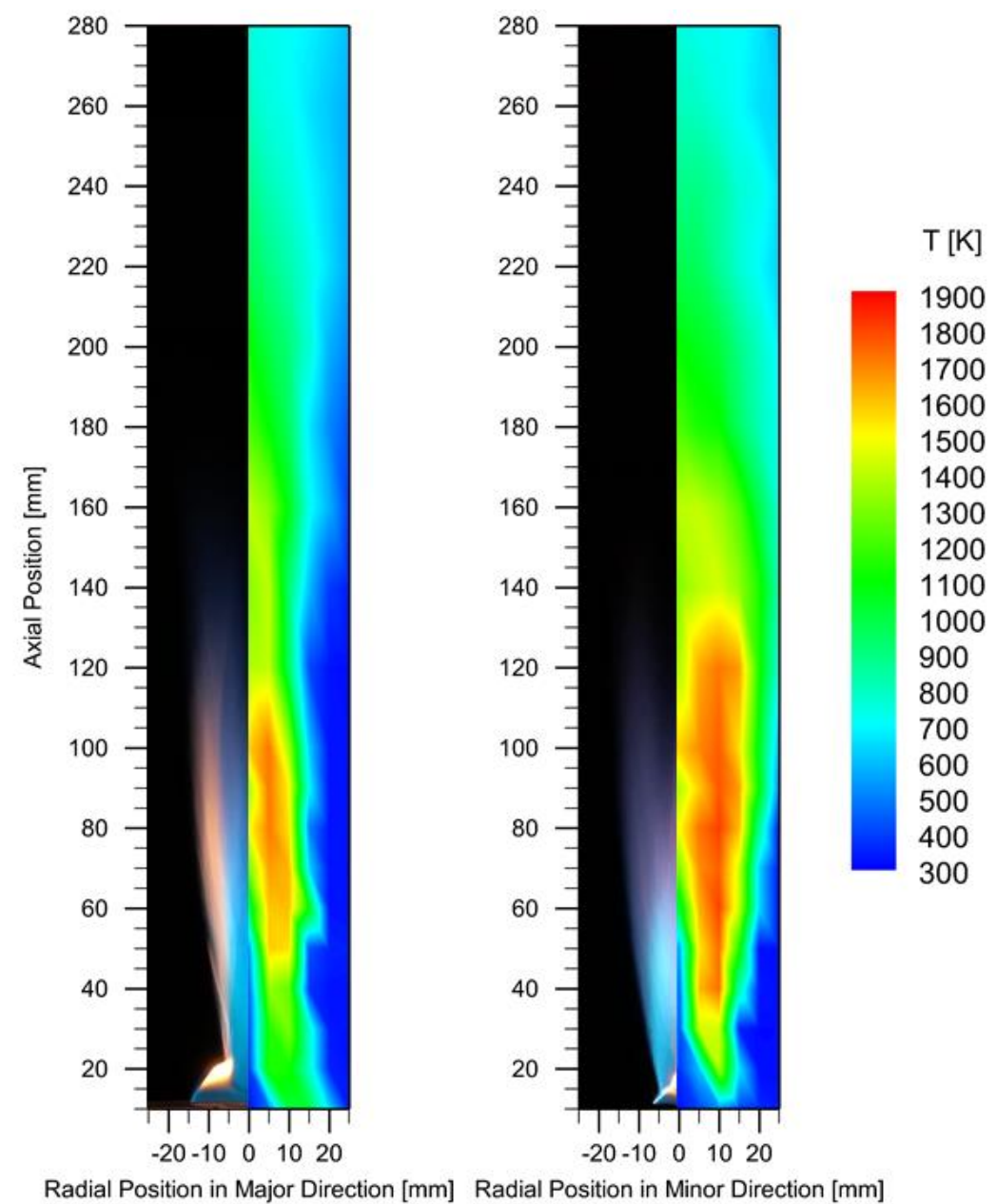

Figure (14) Temperature contours of the IDF at $\bar{V}_{a}=15.58 \mathrm{~m} / \mathrm{s}$ and $\bar{V}_{f}=0.026 \mathrm{~m} / \mathrm{s}$ for both major and minor directions.

\section{Conclusions}

An experimental study is performed to investigate the stability limits and flame structure of IDFs issuing from a concentric circular/elliptic burner. The stability limits of IDFs in the present study is implemented by varying central air velocity at a constant fuel velocity. The influences of varying central air velocity with constant fuel velocity on flame appearance, shadowgraph imaging, flame length, and flame temperature distribution were examined. The major conclusion of this study may be summarized as follows:

(1) The IDF structure comprise base and main flames. The base flame exhibits a pilot flame, which stabilizes the main flame. The base and main flames are separated by flame neck region with a soot ring around the flame neck. The appearance of IDFs characterizes dual structure (a bluish reaction zone confined in a diffusion combustion zone).

(2) The flame stability comprises four stages, yellow flame, blue flame, local flame extinction and re-ignition, and main flame extinction zones. It was found that the blue flame zone lies above the yellow flame zone up to the air velocity value of $22 \mathrm{~m} / \mathrm{s}$. Also, the air velocity of $22 \mathrm{~m} / \mathrm{s}$ in conjunction with the fuel properties forms a strain rate limit for the stable blue flames. 
(3) The main flame faces local extinction and re-ignition (flame tearing) at higher air velocity greater than $22 \mathrm{~m} / \mathrm{s}$. The main flame extinction zone occurs for air velocity higher than $32 \mathrm{~m} / \mathrm{s}$. furthermore, at a high air jet velocity, the main flame extinguishes from the flame neck resulting the base flame to remain attached to the burner rim preventing flame lift-off.

(4) The visual analysis showed that with increasing the air velocity, the luminous zone, soot ring at the top of the base flame decreases and the flame becomes thinner. Also, the flame length decreases because of the improved fuel entrainment. Shadow graph imaging of the flames show increased corrugation in the flames due to shorter flame with higher air velocity.

(5) The peak mean centerline temperature decreases by up to $17.5 \%$ with increasing the air velocity. Moreover, the highest radial temperature on the minor axis is higher than that on the major axis due to the non-homogenous fuel distribution (elliptical fuel tube).

\section{References}

[1] V. Patel and R. Shah, 2019, "Effect of swirl and number of swirler vanes on combustion characteristics of methane inverse diffusion flame", J. Mech. Sci. Technol., vol. 33, no. 4, pp. 1947-1958, doi: 10.1007/s12206-019-0345-7.

[2] V. Patel and R. Shah, 2018, "Experimental investigation on flame appearance and emission characteristics of LPG inverse diffusion flame with swirl", Appl. Therm. Eng., vol. 137, pp.377-385,doi: 10.1016/j.applthermaleng.2018.03.105.

[3] V. Hariharan and D. P. Mishra, 2020, "Static flame stability of circumferentially arranged fuel port inverse jet non-premixed flame burner", Combust. Sci. Technol., vol. 192, no. 8, pp. 1493-1519, , doi: 10.1080/00102202.2019.1611567.

[4] A. M. Elbaz and W. L. Roberts, 2016, "Experimental study of the inverse diffusion flame using high repetition rate OH/acetone PLIF and PIV',Fuel, vol. 165, pp. 447-461, doi: 10.1016/j.fuel.2015.10.096.

[5] L. K. Sze, C. S. Cheung, and C. W. Leung, 2006, "Appearance, temperature, and NOx emission of two inverse diffusion flames with different port design", Combust. Flame, vol. 144, no. 1-2, pp. 237-248, doi: 10.1016/j.combustflame. 2005.07.008.

[6] W. KT and E. RH, 1984, "Mapping and structure of inverse diffusion flames of methane", in Proceeding of the proceedings of the $20^{\text {th }}$ International symposium on combustion, the combustion institute, pp. 1925-32.

[7] S. Mahesh and D. P. Mishra, 2008, "Flame stability and emission characteristics of turbulent LPG IDF in a backstep burner", Fuel, vol. 87, no. 12, pp. 2614-2619, doi: 10.1016/j.fuel.2008.02.001.

[8] S. Mahesh and D. P. Mishra, 2011, "Study of the turbulent inverse diffusion flame in recessed backstep and coaxial burners", Combust. Explos. Shock Waves, vol. 47, no. 3, pp. 274-279, doi: 10.1134/S0010508211030038. 
[9] A. M. Elbaz and W. L. Roberts, 2014, "Flame structure of methane inverse diffusion flame”, Exp. Therm. Fluid Sci., vol. 56, pp. 23-32, doi: 10.1016/j.expthermflusci.2013.11.011.

[10] S. Mahesh and D. P. Mishra, 2015, "Flame stability limits and near blowout characteristics of CNG inverse jet flame”, Fuel, vol. 153, no. February, pp. 267275, doi: 10.1016/j.fuel.2015.02.074.

[11] M. A. Mikofski, T. C. Williams, C. R. Shaddix, and L. G. Blevins, 2004 "Effect of varied air flow on flame structure of laminar inverse diffusion flame",Combust. Inst., pp. 04S - 7 .

[12] M. A. Mikofski, T. C. Williams, C. R. Shaddix, and L. G. Blevins, 2006, "Flame height measurement of laminar inverse diffusion flames", Combust. Flame, vol. 146, no. 1-2, pp. 63-72, doi: 10.1016/j.combustflame.2006.04.006.

[13] A. Sobiesiak and J. C. Wenzell, 2005, "Characteristics and structure of inverse flames of natural gas" ,Proc. Combust. Inst., vol. 30, no. 1, pp. 743-749, doi: 10.1016/j.proci.2004.08.173.

[14] S. Mahesh and D. P. Mishra, 2010, "Flame structure of LPG-air Inverse Diffusion Flame in a backstep burner", Fuel, vol. 89, no. 8, pp. 2145-2148, doi: 10.1016/j.fuel.2010.01.030.

[15] A. M. Elbaz and W. L. Roberts, 2014, "Experimental characterization of methane inverse diffusion flame", Combust. Sci. Technol., vol. 186, no. 9, pp. 1249-1272, doi: 10.1080/00102202.2014.920835.

[16] L. L. Dong, C. S. Cheung, and C. W. Leung, 2007, "Heat transfer characteristics of an impinging inverse diffusion flame jet-Part I: Free flame structure", Int. J. HeatMassTransf.,vol.50,no.25-26,pp.5108-5123,Dec,doi:

10.1016/j.ijheatmasstransfer.2007.07.018.

[17] h. S. Zhen, c. W. Leung, and c. S. Cheung, 2010, "thermal and emission characteristics of a turbulent swirling inverse diffusion flame", int. J. Heat mass transf.,vol.53,no.5-6,pp.902-909, doi: 10.1016/j.ijheatmasstransfer.2009.11.034.

[18] H. S. Zhen, C. W. Leung, and C. S. Cheung, 2011, "A comparison of the thermal, emission and heat transfer characteristics of swirl-stabilized premixed and inverse diffusion flames", Energy Convers. Manag., vol. 52, no. 2, pp. 1263-1271, doi: 10.1016/j.enconman.2010.09.023.

[19] B. Stelzner, F. Hunger, S. Voss, J. Keller, C. Hasse, and D. Trimis, 2013, "Experimental and numerical study of rich inverse diffusion flame structure" ,Proc.Combust.Inst.,vol.34,no.1,pp.1045-1055,doi: 10.1016/j.proci.2012.06.153.

[20] V. Patel and R. Shah,2017, "Experimental and Numerical Investigation of LPG Fuelled Inverse Diffusion Flame in a Coaxial Burner", Adv. Thermofluid Res., vol. 3, no. 1, pp. 16-29.

[21] B. D. Baird and S. R. Gollahalli, 2003,“ Effect of aspect ratio on stability and global emission characteristics of pre-mixed elliptical burner flames", 1 st Int. Energy Convers. Eng. Conf. IECEC, pp. 1-6,doi: 10.2514/6.2003-5948. 
[22] B. D. Baird and S. R. Gollahalli, 2006, "Effects of temperature and hydroxyl radical concentration distributions on emissions of partially premixed flames from elliptical burners", Proc. ASME Turbo Expo, vol. 1, pp. 51-56, doi: 10.1115/GT2006-90065.

[23] P. Hariharan, C. Periasamy, and S. R. Gollahalli, 2007, "Effect of elliptic burner geometry and air equivalence ratio on the nitric oxide emissions from turbulent hydrogen flames", Int. J. Hydrogen Energy, vol. 32, no. 8, pp. 1095-1102, doi: 10.1016/j.ijhydene.2006.07.009.

[24] S. K. S. Chinthamony, C. Periasamy, and S. R. Gollahalli, 2007, "Stability and global emission characteristics of elliptic burner diffusion flames in an elliptic co-flow", Collect. Tech. Pap. - 45th AIAA Aerosp. Sci. Meet., vol. 11, no. January, pp. 7200-7209, doi: 10.2514/6.2007-599.

[25] O. A. Kashkousha, M. M. Kamal, A. M. Abdulaziz, and M. A. Nosier, 2012, "Concentric elliptical jet diffusion flames with co- and cross-flows", Exp. Therm. Fluid Sci., vol. 41, pp. 177-187, doi: 10.1016/j.expthermflusci.2012.03.033.

[26] A. M. R. Attia, H. S. Ayoub, and B. Ghazolin, 2018, "In-Situ Soot visualization using Low power 405nm laser shadowgraphy for premixed and non-premixed flames", Phys. AUC, vol. 28, pp. 12-16.

[27] H. E. Saleh, 2008, "Effect of variation in LPG composition on emissions and performance in a dual fuel diesel engine", Fuel, vol. 87, no. 13-14, pp. 30313039, doi: 10.1016/j.fuel.2008.04.007.

[28] A. M. Elbaz, H. A. Moneib, K. M. Shebil, and W. L. Roberts, 2019, “Low NOX LPG staged combustion double swirl flames", Renew. Energy, vol. 138, no. X, pp. 303-315, doi: 10.1016/j.renene.2019.01.070.

[29] Y. A. Cengel, "Heat Transference a Practical Approach," MacGraw-Hill, vol. 4, no. 9, p. 874, 2004.

[30] F. C. Lockwood and H. A. Moneib, 1982, "Fluctuating temperature measurements in turbulent jet diffusion flame", Combust. Flame, vol. 47, no. C, pp. 291-314, doi: 10.1016/0010-2180(82)90108-0.

[31] L. L. Dong, C. S. Cheung, and C. W. Leung, 2011, “Combustion optimization of a port-array inverse diffusion flame jet", Energy, vol. 36, no. 5, pp. 2834-2846, doi: 10.1016/j.energy.2011.02.025.

[32] V. Hariharan and D. P. Mishra, 2020,"Experimental Characterization of Circumferentially Arranged Fuel Port Inverse Jet Diffusion Flame Burner",Combust.Sci.Technol.,vol.192,no.12,pp.2306-2325,doi: 10.1080/00102202.2019.1643847.

[33] H. S. Zhen, C. S. Cheung, C. W. Leung, and H. B. Li, 2013, "Thermal and heat transfer behaviors of an inverse diffusion flame with induced swirl", Fuel, vol. 103, pp. 212-219, doi: 10.1016/j.fuel.2012.05.026. 